\title{
Access to healthcare for people aged 50+ in Europe during the COVID-19 outbreak
}

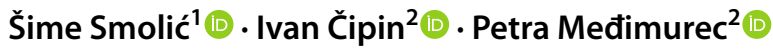 \\ Accepted: 31 May 2021 / Published online: 11 June 2021 \\ (c) The Author(s), under exclusive licence to Springer Nature B.V. 2021
}

\begin{abstract}
This paper combines SHARE Corona Survey and SHARE Wave 7 data for 25 European countries and Israel $(N=40,919)$ with institutional and epidemic-related country characteristics to investigate healthcare access for Europeans aged 50+ during the outbreak of COVID-19. We use a micro-macro approach to examine whether and to what extent barriers to accessing healthcare measured by reported unmet healthcare needs vary within and between countries. We consider various aspects of barriers and distinguish among: (1) respondents who forewent medical treatment because they were afraid of becoming infected with the Coronavirus; (2) respondents who had pre-scheduled medical appointments postponed by health providers due to the outbreak; and (3) respondents who tried to arrange a medical appointment but were denied one. Limited access to healthcare during the initial outbreak was more common for the occupationally active, women, the more educated and those living in urban areas. A bad economic situation, poor overall health and higher healthcare utilisation were robust predictors of unmet healthcare. People aged 50+ in countries of 'Old' Europe, countries with higher universal health coverage and stricter containment and closure policies were more likely to have medical services postponed. Policymakers should address the healthcare needs of older people with chronic health conditions and a poor socio-economic status who were made more vulnerable by this pandemic. In the aftermath of the health crisis, public health systems might experience a great revival in healthcare demand, a challenge that should be mitigated by careful planning and provision of healthcare services.
\end{abstract}

Keywords SHARE Corona Survey $\cdot$ Pandemic $\cdot$ Healthcare access $\cdot$ Older people $\cdot$ Europe

\section{Introduction}

Access to healthcare that can be easily captured by unmet healthcare need is considered as one of the most important achievements of health systems in developed countries (Allin et al. 2010; OECD 2019). It is related to gaining appropriate healthcare resources in order to preserve or improve individual health (Gulliford et al. 2002). The concept of access to healthcare can be described as the 'ability to secure a specified range of services, at a specified level

Responsible editor: Matthias Kliegel

Šime Smolić

ssmolic@efzg.hr

1 Faculty of Economics \& Business, Department of Macroeconomics and Economic Development, University of Zagreb, Zagreb, Croatia

2 Faculty of Economics \& Business, Department of Demography, University of Zagreb, Zagreb, Croatia of quality' (Goddard and Smith 2001: 1151). According to the equity principle, persons in equal need of healthcare should have equal access to it (Oliver and Mossailos 2004). If access to health services is inadequate, for example, due to organisational, financial or cultural reasons, it might have detrimental social, physical or economic consequences (Neri and Kroll 2003; OECD 2019). Unmet healthcare needs might result in poorer self-reported health (Ko 2016), sustain poverty as poor people have less access to health services (Peters et al. 2008) and increase health inequalities because health declines much faster in those with unmet care (Quesnel-Vallée et al. 2016). At the beginning of 2020, the world confronted a completely different type of barrier to access and the utilisation of health services-the onset of the severe acute respiratory syndrome coronavirus 2 (SARS-CoV-2) that was declared a global pandemic on 11 March 2020 (WHO 2020a). Healthcare capacities in many developed countries became overwhelmed by the outbreak (Kissler et al. 2020; Paterlini 2020; Tanne et al. 2020; Volpato et al. 2020). 
Increased burdens on health systems resulted in unprecedentedly high barriers to accessing healthcare for health conditions otherwise unrelated to COVID-19. A global survey on continuity of essential health services during the COVID-19 pandemic showed that health treatments and prevention services for noncommunicable diseases (NCDs) were significantly discontinued or reduced (WHO 2020b). Many recent studies have confirmed disruptions in the provision of different types of health services caused by epidemic control measures (Angelico et al. 2020; De Rosa et al. 2020). It is believed that in the long-run, discontinued healthcare might potentially lead to serious health consequences for some individuals (Palmer et al. 2020). In addition, this pandemic revealed that people with underlying health conditions were more likely to experience severe consequences of the infection (Clark et al. 2020); for example, people diagnosed with diabetes, cardiovascular diseases, chronic respiratory conditions and cancer have been at higher risk for severe COVID-19 and death (WHO and UNDP 2020). Moreover, Douglas et al. (2020) pointed out that the health of older people is at particular risk due to the pandemic control measures because they are at the '...highest direct risk of severe COVID-19, they are more likely to live alone, less likely to use online communications and at risk of social isolation' (p. 2).

Older persons with multiple chronic diseases might be more disadvantaged when it comes to meeting their healthcare needs, especially in ageing societies (Bergman et al. 2013). A more specific study by de Meijer et al. (2013) indicated that the 'relationship between age and the determinants of need, for instance poor health status and disability' (p. 359) was important in explaining health spending profiles by age. This notion also arises from the fact that older persons on average have greater healthcare needs than younger age groups, resulting in health demand and health expenditure in most developed countries to steepen around the age of early to mid-60 s (Eurostat, 2016; Williams et al. 2019). For example, nearly four out of every ten EU citizens were aged 50+ in 2019 (Eurostat 2020a), but this age group in comparison with younger ages takes up the largest proportion of total healthcare expenditures (Williams et al. 2019).

Despite almost universal healthcare coverage across Europe, certain socio-demographic groups are more likely to receive inadequate health services or access to healthcare than others (Cylus and Papanicolas 2015). Studies based on data from the Survey of Health, Ageing and Retirement in Europe (SHARE) suggest that older people may have higher healthcare needs or use more medical services due to their disabilities and chronic health conditions, poor socio-economic status or social isolation (Allin et al. 2009; Cantarero-Prieto et al. 2019; Santos-Eggimann et al. 2005; Srakar et al. 2016; Terraneo 2015). Women and individuals with low education and those in disadvantaged socio-economic conditions are more likely to report unmet needs for healthcare (Allin et al. 2009; Siciliani and Verzulli 2009). People with lower socio-economic status are also more likely to forgo medical treatments due to cost (Litwin and Sapir 2009). Not receiving needed medical treatment could potentially be life-threatening and result in death as an outcome. Studies in Spain and Sweden found a significant association between unmet healthcare needs and increased risk of mortality among older people (Alonso et al. 1997; Lindström et al. 2020).

Disparities in unmet health needs are not only reinforced by individual-level factors but can also vary between countries. Access to healthcare is related to differences in countries' economic development and the organisation of the healthcare systems (Chaupain-Guillot and Guillot 2015). However, older people face barriers in accessing healthcare even in countries with universal healthcare coverage, especially people with poor socio-economic conditions, who are homebound or who have chronic conditions (Doetsch et al. 2017; Herr et al. 2014; Osborn et al. 2014). For instance, the EU-SILC data from 2019 show that nearly $4 \%$ of EU citizens aged $65+$ reported an unmet need for healthcare, ranging from $0.4 \%$ in Spain and Germany to $19.6 \%$ in Estonia (Eurostat 2020b).

The outbreak of COVID-19 and the measures that have been implemented against it within national healthcare systems call for a better understanding of unmet healthcare needs and related determinants among older people. In doing so, this paper uses a unique SHARE Corona Survey dataset (Börsch-Supan 2020a) and combines it with available COVID-19-related and institutional macro-level data to investigate access to healthcare for Europeans aged 50+during the outbreak of the novel Coronavirus. We consider various aspects of access to healthcare and distinguish between:

(1) whether respondents themselves decided to forgo medical treatment because they were afraid of becoming infected with the Coronavirus;

(2) whether health providers or medical facilities postponed respondents' pre-scheduled medical appointments due to the pandemic; and

(3) whether respondents tried to arrange a medical appointment but were denied one because of the pandemic.

The paper employs the SHARE database by linking the available pre-pandemic characteristics of the population aged 50+ with their experiences of accessing healthcare during the initial wave of the pandemic. We aim to identify the subpopulations of older people for whom the COVID19 crisis and subsequently congested healthcare capacities and vast disruption in healthcare utilisation made access to health services even more difficult. In addition, we examine the extent of unmet healthcare needs in the countries 
of 'New' and 'Old' Europe to understand better the ability to cope with the health crisis. We use the terms 'Old' and 'New' Europe to distinguish between post-socialist EU countries and old EU member countries before 2004 plus Cyprus and Malta. Israel and Switzerland are exceptions and were classified as 'Old' European countries (see Table 2 for a complete list of countries). Given the fact that Europe is still far from having a common healthcare system, we also focus on identifying whether the Bismarck and the Beveridge healthcare systems differ in respect to unmet health needs resulting from the epidemic control measures.

The main objective of this article is to examine whether and to what extent barriers to accessing healthcare due to COVID-19 as measured by reported unmet healthcare needs vary within and between countries. We use a micro-macro approach to answer the following research questions:

Micro: What are the determinants of limited access to healthcare due to COVID-19 at the individual level? Which groups of people aged 50+ were more likely to report unmet healthcare needs in the course of the pandemic?

Macro: How do barriers to healthcare during the outbreak of COVID-19 differ across European countries and Israel? Does the country-specific context, both COVID-19-related and social and institutional, explain between-country differences? Can we observe typical patterns related to access to healthcare for older people in the 'New' Europe and in the 'Old' Europe?

In what follows, we primarily draw on the situation in the first wave of the pandemic when most European countries applied lockdown policies with different degrees of stringency. In this respect, our analysis will reveal if and where Corona lockdowns in the spring of 2020 made the particularly vulnerable elders even more vulnerable.

\section{Data and methods}

Our analysis focused on SHARE respondents aged 50+ who participated in the SHARE Corona Survey (Börsch-Supan 2020a) and in the regular SHARE Wave 7 (Börsch-Supan 2020b; Börsch-Supan et al. 2013). The SHARE Corona Survey asked various questions about key life domains affected by the COVID-19 outbreak, including questions about access to healthcare during the outbreak (Scherpenzeel et al. 2020). We combined data from the SHARE Corona Survey with the SHARE Wave 7 data to obtain all individual-level characteristics required for the current analysis. We removed cases with missing values on any of the measures, which left us with a sample of 40,919 respondents aged 50+ from 26 countries. This provides a good design to examine both within- and between-country differences in access to healthcare for older Europeans during the outbreak of COVID-19.
We used STATA 16 (StataCorp 2019) for data processing and statistical analysis. All STATA logs (i.e. annotated STATA outputs) are available from the authors upon request. The plots were produced using the ggplot2 package (Wickham 2016) in R (R Core Team 2020).

\section{Micro-level explanatory variables}

Because access to healthcare is a multifaceted and complex phenomenon (Andersen 1995), we considered individuallevel explanatory variables from three broad groups. The first group was comprised of variables on basic socio-demographics: age (occupationally active: ages 50-64; young retirees: ages 65-79 and the older-old: age $80+$ ), gender, education (low, medium or high, based on ISCED 2011 classification of country-specific educational categories collected by SHARE), living arrangements (does not live alone vs. lives alone) and area of residence (rural vs. urban, with rural denoting the 'rural area or village' category from the SHARE Wave 7 questionnaire).

The second group of explanatory variables was comprised of measures of socio-economic status, including self-reported job situation and the ability to make ends meet since the outbreak. The former was recoded to distinguish between retired, working (employed or self-employed) and other SHARE respondents (unemployed, permanently sick or disabled, homemakers and others). As for the latter, SHARE interviews persons aged 50+ and their partners (regardless of their age) within the same household and for the interview, each SHARE-participating household appoints one eligible respondent as its household respondent. This respondent answers a specific set of householdrelated questions-including the ability to make ends meet - on behalf of the entire household. To allow for individual-level data analysis, we copied the answers as provided by the household respondents to their partners within the same household (who participated in the survey, but did not answer this specific set of household-related questions).

The third group of explanatory variables was comprised of health-related measures. We included the following in our models: self-rated health (SRH) before the outbreak (ranging from excellent to poor), change in SRH since the outbreak (respondents answered whether their health improved/ worsened or stayed about the same), dummy variables indicating whether the respondent was diagnosed with a major illness since the last interview, for example, cancer, cardiovascular disease, chronic lung disease or hip fracture (see the SHARE Corona Survey questionnaire for a full list), whether the respondent regularly takes prescription drugs $(0=$ No, $1=$ Yes $)$, the number of times the respondent was a hospital patient within the last 12 months as of SHARE Wave 7 (none, 1, 2 or $3+$ ), the number of limitations on the activities of daily living (ADL) and instrumental activities of 
daily living (IADL) (none vs. 1+) and the number of chronic conditions (less than 2 diseases vs. $2+$ chronic conditions). Descriptive information on the micro-level variables is provided in Table 1.

\section{Macro-level explanatory variables}

To investigate whether and to what extent country-specific contexts matter in explaining how barriers to accessing healthcare during the outbreak of COVID-19 varied for older persons across European countries, we combined individuallevel SHARE data with Corona-related and social and institutional country-specific characteristics. We drew data from the European Centre for Disease Prevention and Control (ECDC 2020) to measure the morbidity (the total number of cases per 100,000 population) and mortality (the total number of deaths per 100,000 population) ${ }^{1}$ of COVID-19 until 31 May 2020. We chose this date as a cut-off because SHARE started conducting COVID-19 interviews early in June 2020 (Börsch-Supan 2020c).

In addition to COVID-19 morbidity and mortality measures, we considered the characteristics of the countries' healthcare systems. In our analysis, we distinguished between the Beveridge (national health service, mostly taxfinanced) and Bismarck (social security systems funded by compulsory contributions) models of healthcare. We further considered the universal health coverage (UHC) effective coverage index (Lozano et al. 2020) in an effort to capture how effective health service is at the population level. The UHC effective coverage index is reported on a scale of $0-100$, with higher scores indicating higher service coverage.

We used the Containment and Health Index (CHI) - a composite measure produced by the Oxford COVID-19 Government Response Tracker (OxCGRT) - to account for differences in the strictness of government policies related to COVID-19 (Hale et al. 2020) and to test whether and how such policies reflected on access to healthcare for older Europeans. CHI combines indicators of containment and closure policies and indicators of health system policies into a single measure ranging from 0 to 100 , with higher scores indicating stricter government responses. Finally, we looked for differences in access to healthcare between 'Old' and 'New' European countries. Table 2 presents descriptive information on all macro-level variables used in our analysis.

\section{Outcome variables and models}

We examined three different outcomes to account for various aspects of limits in access to healthcare due to the Coronavirus. All three outcomes are binary and are presented, by country, in Fig. 1:

Outcome 1: Since the outbreak of Corona, did you forgo medical treatment because you were afraid to become infected by the corona virus? $(0=$ No, $1=$ Yes $)$.

Outcome 2: Did you have a medical appointment scheduled, which the doctor or medical facility decided to postpone due to Corona? $(0=\mathrm{No}, 1=\mathrm{Yes})$.

Outcome 3: Did you ask for an appointment for a medical treatment since the outbreak of Corona and did not get one? $(0=$ No, $1=$ Yes $)$.

Our analysis proceeded in several steps. We first estimated a series of pooled logistic regression models with country controls. We then used multilevel techniques to estimate multilevel logistic regression models in which individuals are nested in countries. We allowed the intercepts to vary across countries. We compared the pooled regression results to multilevel results (see Table 3 in the Results section). This step of the analysis allowed us to address the determinants of limited access to healthcare due to COVID19 at the individual level and to identify the groups of people aged $50+$ that were more likely to report unmet healthcare needs in the course of the pandemic. In the next step, we used multilevel models to study the effects of variables at the country level on the odds of forgoing a medical treatment (outcome 1), having a medical appointment postponed (outcome 2) or being denied a medical appointment (outcome 3) due to the Coronavirus. Because of the correlations between the macro-level explanatory variables (results available from the authors upon request), we added the macro-variables to each model one by one. This step of the analysis allowed us to consider the role of country-specific context, both COVID-19-related and social and institutional, in explaining between-country differences in access to healthcare-while taking account of individual background characteristics.

One should note that we were unable to differentiate between respondents with no need for healthcare and respondents with a met need for healthcare. Our estimates of difficulties in accessing healthcare during the pandemic might therefore be biased downwards, because the denominator includes respondents who had no need for healthcare in the first place. However, we believe that this survey design limitation affects descriptive statistics more than it affects our multivariate findings, which, we believe, will still be very useful in revealing within- and between-country variations in access to healthcare during the COVID-19 pandemic.

\footnotetext{
1 We used 2019 population estimates.
} 
Table 1 Description of the micro-level SHARE study variables

\begin{tabular}{|c|c|c|}
\hline & Frequency & Per cent \\
\hline \multicolumn{3}{|l|}{ Age } \\
\hline $50-64$ & 11,460 & 28.01 \\
\hline $65-79$ & 21,964 & 53.68 \\
\hline $80+$ & 7495 & 18.32 \\
\hline \multicolumn{3}{|l|}{ Gender } \\
\hline Male & 17,090 & 41.77 \\
\hline Female & 23,829 & 58.23 \\
\hline \multicolumn{3}{|c|}{ Education (SHARE w7) } \\
\hline Low & 13,947 & 34.08 \\
\hline Medium & 17,619 & 43.06 \\
\hline High & 9353 & 22.86 \\
\hline \multicolumn{3}{|c|}{ Living arrangements (SHARE w7) } \\
\hline Does not live alone & 32,141 & 78.55 \\
\hline Lives alone & 8778 & 21.45 \\
\hline \multicolumn{3}{|c|}{ Area of residence (SHARE w7) } \\
\hline Rural & 15,519 & 37.93 \\
\hline Urban & 25,400 & 62.07 \\
\hline \multicolumn{3}{|c|}{ Job situation (SHARE w7) } \\
\hline Retired & 24,884 & 60.81 \\
\hline Working & 9867 & 24.11 \\
\hline Other & 6168 & 15.07 \\
\hline \multicolumn{3}{|c|}{ Ability to make ends meet since outbreak } \\
\hline With great difficulty & 3747 & 9.16 \\
\hline With some difficulty & 10,635 & 25.99 \\
\hline Fairly easily & 14,549 & 35.56 \\
\hline Easily & 11,988 & 29.30 \\
\hline \multicolumn{3}{|c|}{ Self-rated health (SRH) before the outbreak } \\
\hline Excellent & 2684 & 6.56 \\
\hline Very good & 6489 & 15.86 \\
\hline Good & 18,080 & 44.18 \\
\hline Fair & 10,811 & 26.42 \\
\hline Poor & 2855 & 6.98 \\
\hline \multicolumn{3}{|c|}{ Change in SRH since Corona } \\
\hline About the same & 36,029 & 88.05 \\
\hline Improved & 1177 & 2.88 \\
\hline Worsened & 3713 & 9.07 \\
\hline \multicolumn{3}{|c|}{ Diagnosed with a major illness since last interview } \\
\hline Yes & 4420 & 10.80 \\
\hline No & 36,499 & 89.20 \\
\hline \multicolumn{3}{|c|}{ Regularly takes prescription drugs } \\
\hline Yes & 31,819 & 77.76 \\
\hline No & 9100 & 22.24 \\
\hline \multicolumn{3}{|c|}{ Times a hospital patient within last 12 months (SHARE w7) } \\
\hline None & 35,420 & 86.56 \\
\hline 1 & 3817 & 9.33 \\
\hline 2 & 945 & 2.31 \\
\hline $3+$ & 737 & 1.80 \\
\hline \multicolumn{3}{|l|}{ ADL limitations } \\
\hline No ADL limitations & 37,067 & 90.59 \\
\hline $1+\mathrm{ADL}$ limitations & 3852 & 9.41 \\
\hline
\end{tabular}


Table 1 (continued)

\begin{tabular}{llc}
\hline & Frequency & Per cent \\
\hline IADL limitations & & \\
No IADL limitations & 34,698 & 84.80 \\
1+ IADL limitations & 6221 & 15.20 \\
Chronic conditions & & \\
Less than 2 diseases & 19,839 & 48.48 \\
$2+$ chronic diseases & 21,080 & 51.52 \\
\hline
\end{tabular}

Unweighted values based on combined data from SHARE Wave 7 Release 7.1.1, SHARE Corona Survey Release 0.0 .1 beta

Table 2 Description of the macro-level variables: COVID-19-related and institutional country characteristics, by country

\begin{tabular}{|c|c|c|c|c|c|c|c|}
\hline & Sample size ${ }^{\mathrm{a}}$ & $\begin{array}{l}\text { COVID-19 } \\
\text { morbidity }\end{array}$ & $\begin{array}{l}\text { COVID-19 } \\
\text { mortality }\end{array}$ & Healthcare system & UHC index & $\mathrm{CHI}^{\mathrm{c}}$ & $\begin{array}{l}\text { 'Old' versus } \\
\text { 'New' Europe }\end{array}$ \\
\hline Belgium & 3192 & 514.58 & 81.66 & Bismarck & 87 & 62.46 & 'Old' Europe \\
\hline Bulgaria & 756 & 35.90 & 2.00 & Bismarck & 63 & 54.04 & 'New' Europe \\
\hline Croatia & 1700 & 55.10 & 2.53 & Bismarck & 79 & 68.72 & 'New' Europe \\
\hline Cyprus & 556 & 107.66 & 1.94 & Beveridge & 80 & 69.76 & 'Old' Europe \\
\hline Czech Republic & 2138 & 86.67 & 3.00 & Bismarck & 82 & 62.69 & 'New' Europe \\
\hline Denmark & 1788 & 200.36 & 9.83 & Beveridge & 84 & 55.08 & 'Old' Europe \\
\hline Estonia & 3352 & 140.77 & 4.76 & Bismarck & 82 & 49.52 & 'New' Europe \\
\hline Finland & 1158 & 123.71 & 5.73 & Beveridge & 91 & 47.74 & 'Old' Europe \\
\hline France & 1685 & 226.07 & 42.93 & Bismarck & 91 & 67.24 & 'Old' Europe \\
\hline Germany & 2370 & 218.60 & 10.24 & Bismarck & 86 & 58.34 & ‘Old' Europe \\
\hline Greece & 2280 & 27.18 & 1.63 & Bismarck & 80 & 57.43 & 'Old' Europe \\
\hline Hungary & 660 & 39.57 & 5.36 & Bismarck & 72 & 60.43 & 'New' Europe \\
\hline Israel & 963 & 199.69 & 3.33 & Bismarck & 81 & 70.52 & 'Old' Europe \\
\hline Italy & 2878 & 385.46 & 55.24 & Beveridge & 89 & 74.25 & 'Old' Europe \\
\hline Latvia & 849 & 55.47 & 1.25 & Beveridge & 70 & 52.07 & 'New' Europe \\
\hline Lithuania & 1093 & 59.77 & 2.51 & Bismarck & 70 & 62.77 & 'New' Europe \\
\hline Luxembourg & 667 & 654.18 & 17.92 & Bismarck & 91 & 62.07 & 'Old’ Europe \\
\hline Malta & 702 & 125.01 & 1.82 & Beveridge & 83 & 72.50 & 'Old' Europe \\
\hline Poland & 2628 & 62.07 & 2.79 & Bismarck & 73 & 60.90 & 'New' Europe \\
\hline Portugal & 815 & 313.36 & 13.58 & Beveridge & 84 & 63.78 & 'Old' Europe \\
\hline Romania & 1259 & 98.55 & 6.45 & Bismarck & 70 & 61.47 & 'New' Europe \\
\hline Slovakia & 743 & 27.91 & 0.51 & Bismarck & 78 & 64.00 & 'New' Europe \\
\hline Slovenia & 2545 & 70.79 & 5.19 & Bismarck & 90 & 64.80 & 'New' Europe \\
\hline Spain & 1509 & 510.11 & 57.79 & Beveridge & 90 & 63.40 & 'Old' Europe \\
\hline Sweden & 1075 & 375.27 & 44.96 & Beveridge & 90 & 47.72 & 'Old' Europe \\
\hline Switzerland & 1558 & 360.02 & 19.38 & Bismarck & 93 & 54.65 & 'Old' Europe \\
\hline
\end{tabular}

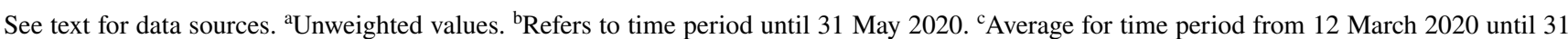
May 2020

In what follows, we present and interpret our findings focusing on two statistics. We begin with odds ratios, the exponentiations of logit coefficients. A positive logit coefficient corresponds to an odds ratio (OR) greater than 1 , while a negative logit coefficient corresponds to an OR less than 1 . In our case, the ORs show how the odds of forgoing a medical treatment (outcome 1) or having a medical treatment postponed (outcome 2) or being denied a medical treatment (outcome 3 ) due to the Coronavirus change with a one-unit increase in the explanatory variable (holding all other explanatory variables constant). To facilitate interpretation, we supplemented the OR estimates with predictive margins, to show how outcome probabilities are 

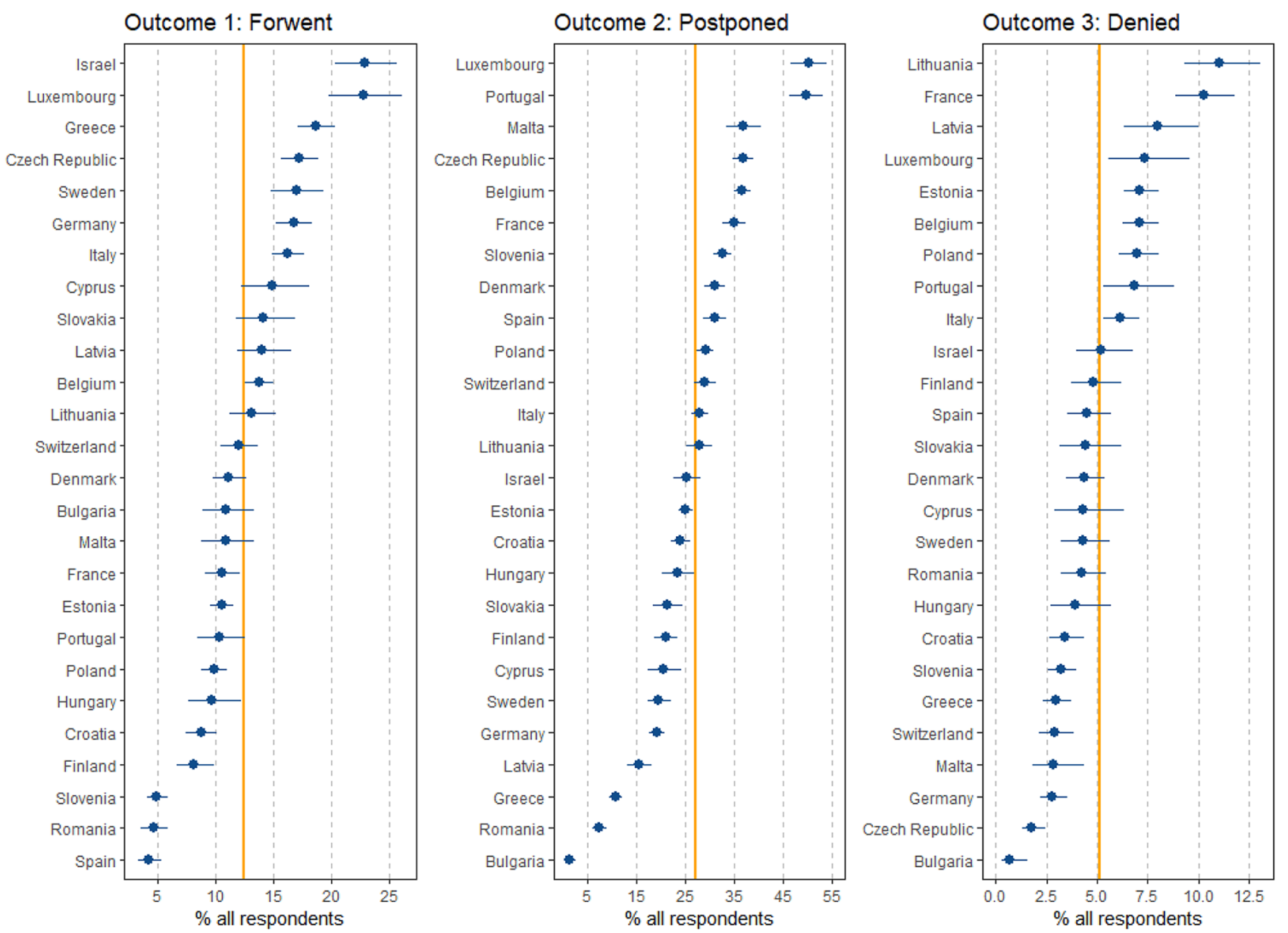

Fig. 1 Outcomes by country. Notes: Own calculations based on combined data from SHARE Wave 7 Release 7.1.1, SHARE Corona Survey Release 0.0 .1 beta $(N=40,919)$. Error bars represent $95 \%$ confidence intervals; the solid vertical line represents the sample average

expected to change with each (at least partially) significant macro-level explanatory variable from our models.

\section{Results}

Overall, $12.4 \%$ of the respondents reported having had forgone healthcare, $27 \%$ had pre-scheduled health services postponed and $5.2 \%$ were denied healthcare services after the outbreak. The unweighted proportions of unmet healthcare needs for outcomes in our analysis varied from $4.2 \%$ in Spain to $22.9 \%$ in Israel (for forgoing medical treatment), from $1.5 \%$ in Bulgaria to $50.4 \%$ in Luxemburg (for postponed scheduled medical appointments) and from $0.7 \%$ in Bulgaria to $11.1 \%$ in Lithuania (for denied medical appointments). There was less between-country variation in unmet healthcare needs due to denied medical appointments than due to postponed or forwent medical treatments (see Fig. 1).

Table 3 presents estimated odds ratios for all factors associated with the three outcome variables of unmet healthcare that were controlled for in this analysis. First, we find that the older-old were least likely to experience barriers in accessing healthcare measured by each of the three outcomes. Precisely, the odds of having healthcare postponed were $36 \%$ lower for the older-old compared with individuals in the reference age group. This finding for postponed healthcare for the older-old is consistent with the results of a simpler model in which we considered age and country effects only (separate analysis not presented here). Being a female proved to be a robust predictor of forgoing and postponement of health services in the outbreak. The effects of education in every single outcome are evident - the higher the person's educational attainment, the greater the odds of reporting forwent, postponed and denied healthcare. People aged 50+ in urban areas were more likely to forgo or to find themselves faced with postponement of scheduled medical treatments. In general, some degree of limited healthcare access during the outbreak of the Coronavirus in Europe was more common among the occupationally active, women, people with 
Table 3 Determinants of limited access to healthcare for older Europeans due to the outbreak of COVID-19

\begin{tabular}{|c|c|c|c|c|c|c|}
\hline & \multicolumn{2}{|c|}{ Outcome 1: Forwent } & \multicolumn{2}{|c|}{ Outcome 2: Postponed } & \multicolumn{2}{|c|}{ Outcome 3: Denied } \\
\hline & Pooled & Multilevel & Pooled & Multilevel & Pooled & Multilevel \\
\hline \multicolumn{7}{|l|}{ Age } \\
\hline $50-64$ & Ref & Ref & Ref & Ref & Ref & Ref \\
\hline $65-79$ & $0.909 * *$ & $0.912 *$ & $0.900 * * *$ & $0.900 * * *$ & $0.881^{*}$ & $0.879 *$ \\
\hline $80+$ & $0.786^{* * *}$ & $0.789 * * *$ & $0.643 * * *$ & $0.643 * * *$ & $0.640 * * *$ & $0.638 * * *$ \\
\hline \multicolumn{7}{|l|}{ Gender } \\
\hline Male & Ref & Ref & Ref & Ref & Ref & Ref \\
\hline Female & $1.543 * * *$ & $1.541 * * *$ & $1.201 * * *$ & $1.201 * * *$ & $1.102 * *$ & $1.102 * *$ \\
\hline \multicolumn{7}{|c|}{ Education (SHARE w7) } \\
\hline Low & $0.826 * * *$ & $0.825 * * *$ & $0.822 * * *$ & $0.823 * * *$ & $0.877 * *$ & $0.879 * *$ \\
\hline Medium & Ref & Ref & Ref & Ref & Ref & Ref \\
\hline High & $1.301 * * *$ & $1.302 * * *$ & $1.156^{* * *}$ & $1.156^{* * *}$ & $1.232 * * *$ & $1.239 * * *$ \\
\hline \multicolumn{7}{|c|}{ Living arrangements (SHARE w7) } \\
\hline Does not live alone & Ref & Ref & Ref & Ref & Ref & Ref \\
\hline Lives alone & 0.983 & 0.984 & 0.967 & 0.967 & 0.999 & 1.003 \\
\hline \multicolumn{7}{|c|}{ Area of residence (SHARE $w 7$ ) } \\
\hline Rural & $0.944 *$ & $0.942 *$ & $0.954 *$ & $0.954 *$ & $0.885^{* *}$ & $0.885 * *$ \\
\hline Urban & Ref & Ref & Ref & Ref & Ref & Ref \\
\hline \multicolumn{7}{|c|}{ Job situation (SHARE w7) } \\
\hline Retired & $1.112 * *$ & $1.109 * *$ & 1.053 & 1.053 & 0.961 & 0.959 \\
\hline Working & Ref & Ref & Ref & Ref & Ref & Ref \\
\hline Other & 0.991 & 0.990 & 0.969 & 0.970 & 1.051 & 1.052 \\
\hline \multicolumn{7}{|c|}{ Ability to make ends meet since outbreak } \\
\hline With great difficulty & $1.415^{* * *}$ & $1.404 * * *$ & 0.984 & 0.977 & $1.406 * * *$ & $1.384 * * *$ \\
\hline With some difficulty & $1.160 * * *$ & $1.152 * * *$ & $0.897 * * *$ & $0.894 * * *$ & 1.087 & 1.082 \\
\hline Fairly easily & 0.998 & 0.993 & $0.930 * *$ & $0.930 * *$ & 1.010 & 1.013 \\
\hline Easily & Ref & Ref & Ref & Ref & Ref & Ref \\
\hline \multicolumn{7}{|c|}{ Self-rated health (SRH) before Corona } \\
\hline Excellent & Ref & Ref & Ref & Ref & Ref & Ref \\
\hline Very good & $1.329 * * *$ & $1.328 * * *$ & 1.094 & 1.094 & $1.396^{* *}$ & $1.397 * *$ \\
\hline Good & $1.503 * * *$ & $1.498 * * *$ & $1.290 * * *$ & $1.289 * * *$ & $1.630 * * *$ & $1.631 * * *$ \\
\hline Fair & $1.936^{* * *}$ & $1.927 * * *$ & $1.608 * * *$ & $1.607 * * *$ & $2.153 * * *$ & $2.161 * * *$ \\
\hline Poor & $2.019 * * *$ & $2.006 * * *$ & $1.581 * * *$ & $1.580 * * *$ & $2.580 * * *$ & $2.598 * * *$ \\
\hline \multicolumn{7}{|c|}{ Change in SRH since Corona } \\
\hline About the same & Ref & Ref & Ref & Ref & Ref & Ref \\
\hline Improved & $1.300 * * *$ & $1.302 * * *$ & $1.293 * * *$ & $1.293 * * *$ & 1.131 & 1.131 \\
\hline Worsened & $1.512 * * *$ & $1.514 * * *$ & $1.238 * * *$ & $1.239 * * *$ & $1.913 * * *$ & $1.919 * * *$ \\
\hline \multicolumn{7}{|c|}{ Diagnosed with a major illness since last interview } \\
\hline Yes & $1.115^{* *}$ & $1.115^{* *}$ & $1.422 * * *$ & $1.421 * * *$ & $1.479 * * *$ & $1.476^{* * *}$ \\
\hline No & Ref & Ref & Ref & Ref & Ref & Ref \\
\hline \multicolumn{7}{|c|}{ Regularly takes prescription drugs } \\
\hline Yes & $1.495 * * *$ & $1.496 * * *$ & $1.876^{* * *}$ & $1.876^{* * * *}$ & $1.270 * * *$ & $1.266^{* * *}$ \\
\hline No & Ref & Ref & Ref & Ref & Ref & Ref \\
\hline \multicolumn{7}{|c|}{ Times a hospital patient within last 12 months (SHARE w7) } \\
\hline None & Ref & Ref & Ref & Ref & Ref & Ref \\
\hline 1 & 0.978 & 0.979 & $1.173 * * *$ & $1.174 * * *$ & $1.140^{*}$ & $1.141^{*}$ \\
\hline 2 & 1.028 & 1.029 & $1.321^{* * *}$ & $1.320 * * *$ & $1.387 * *$ & $1.384 * *$ \\
\hline $3+$ & 1.183 & 1.184 & 1.111 & 1.111 & 1.207 & 1.208 \\
\hline \multicolumn{7}{|l|}{ ADL limitations } \\
\hline No ADL limitations & Ref & Ref & Ref & Ref & Ref & Ref \\
\hline
\end{tabular}


Table 3 (continued)

\begin{tabular}{|c|c|c|c|c|c|c|}
\hline & \multicolumn{2}{|c|}{ Outcome 1: Forwent } & \multicolumn{2}{|c|}{ Outcome 2: Postponed } & \multicolumn{2}{|c|}{ Outcome 3: Denied } \\
\hline & Pooled & Multilevel & Pooled & Multilevel & Pooled & Multilevel \\
\hline $1+\mathrm{ADL}$ limitations & 0.913 & 0.911 & 1.004 & 1.004 & 1.040 & 1.042 \\
\hline \multicolumn{7}{|l|}{ IADL limitations } \\
\hline No IADL limitations & Ref & Ref & Ref & Ref & Ref & Ref \\
\hline 1 + IADL limitations & 1.003 & 1.004 & $0.923 * *$ & $0.923 * *$ & $0.829 * *$ & $0.828 * *$ \\
\hline \multicolumn{7}{|l|}{ Chronic conditions } \\
\hline Less than 2 diseases & Ref & Ref & Ref & Ref & Ref & Ref \\
\hline $2+$ chronic diseases & $1.270 * * *$ & $1.270 * * *$ & $1.258 * * *$ & $1.259 * * *$ & $1.332 * * *$ & $1.333 * * *$ \\
\hline Observations & 40,919 & 40,919 & 40,919 & 40,919 & 40,919 & 40,919 \\
\hline Country controls & Yes & No & Yes & No & Yes & No \\
\hline $\begin{array}{l}\text { Multilevel ICC (from } \\
\text { the null model) }\end{array}$ & - & 0.063 & - & 0.155 & - & 0.077 \\
\hline
\end{tabular}

Odds ratio estimates based on combined data from SHARE Wave 7 Release 7.1.1, SHARE Corona Survey Release 0.0 .1 beta $(N=40,919) ; * p<0.1, * * p<0.05, * * * p<0.01$

higher educational attainment and those living in urban areas.

We observed a statistically significant socio-economic gradient for outcomes 1 and 3. Europeans aged 50+ who reported a bad economic situation, that is, who have experienced difficulties in making ends meet, were more likely to report forgoing medical services due to fear of Coronavirus infection or to have an appointment for a medical treatment denied.

Our set of health-related variables exhibits the expected patterns, with SRH assessed before and perceived change in SRH after the outbreak as the most compelling determinants of barriers in access to healthcare in our sample of Europeans aged $50+$. We found that persons aged $50+$ who reported poorer SRH or worsening SRH in the outbreak were significantly more likely to refrain from getting health services due to fear of infection with the Coronavirus, more likely to have a scheduled medical appointment postponed and an appointment for a medical treatment denied. Next, we identified several characteristics of people aged 50+ who were more vulnerable to this health crisis and had greater likelihood to experience issues in access to healthcare. These include individuals who were diagnosed with a serious illness since the last SHARE interview, those who regularly take prescription drugs and who suffer from two or more chronic conditions. Previous experience of older persons with hospitalisation(s) increases the likelihood of having scheduled medical appointment postponed or having medical treatment denied.

In the null models in our multilevel analysis, the between-country variances in access to healthcare are estimated at $6.3,15.5$ and $7.7 \%$ (outcome 1, outcome 2 and outcome 3 , respectively), as can be observed in the last row from Table 3. This is a measure of how much variation in accessing healthcare during the outbreak of COVID-19 is at the country level. We considered macro-variables to gain additional insight, see Fig. 2 and Table 4.

With Fig. 2, we began our examination of whether the differences in accessing healthcare between countries are associated with contextual variables. We plotted the country-specific proportions of each outcome (y-axis) against the macro-variables (x-axis).

We then proceeded to estimate a series of multilevel random intercept models, with macro-level variables added one by one. The findings are presented in Table 4 . The higher the number of COVID-19 cases per 100,000 inhabitants until 31 May 2020, the higher the likelihood of having a previously scheduled medical appointment postponed or requested medical treatment denied; similarly, the higher the total number of COVID-19 deaths per 100,000 , the higher the likelihood of having an appointment for medical treatment denied. Persons aged 50+ in countries with higher values of the UHC index were more likely to have their scheduled medical treatments postponed due to COVID-19. Furthermore, respondents from 'New' European countries (as compared to respondents from 'Old' European countries) were less likely to forgo medical treatments and to have medical appointment postponed. We also found a significant effect of the CHI, suggesting that more stringent governmental measures against COVID-19 might be associated with a greater chance of healthcare systems pursuing postponements of previously scheduled medical treatments.

To facilitate interpretation and to get a more practical feel for the impact of contextual variables on access to healthcare in logistic regression models, in addition to odds ratio estimates, we considered all significant country-level effects in terms of predicted outcome probabilities at specified values of macro-covariates. In Figs. 3, 4 and 5, we show predicted outcome probabilities with $95 \%$ confidence intervals 

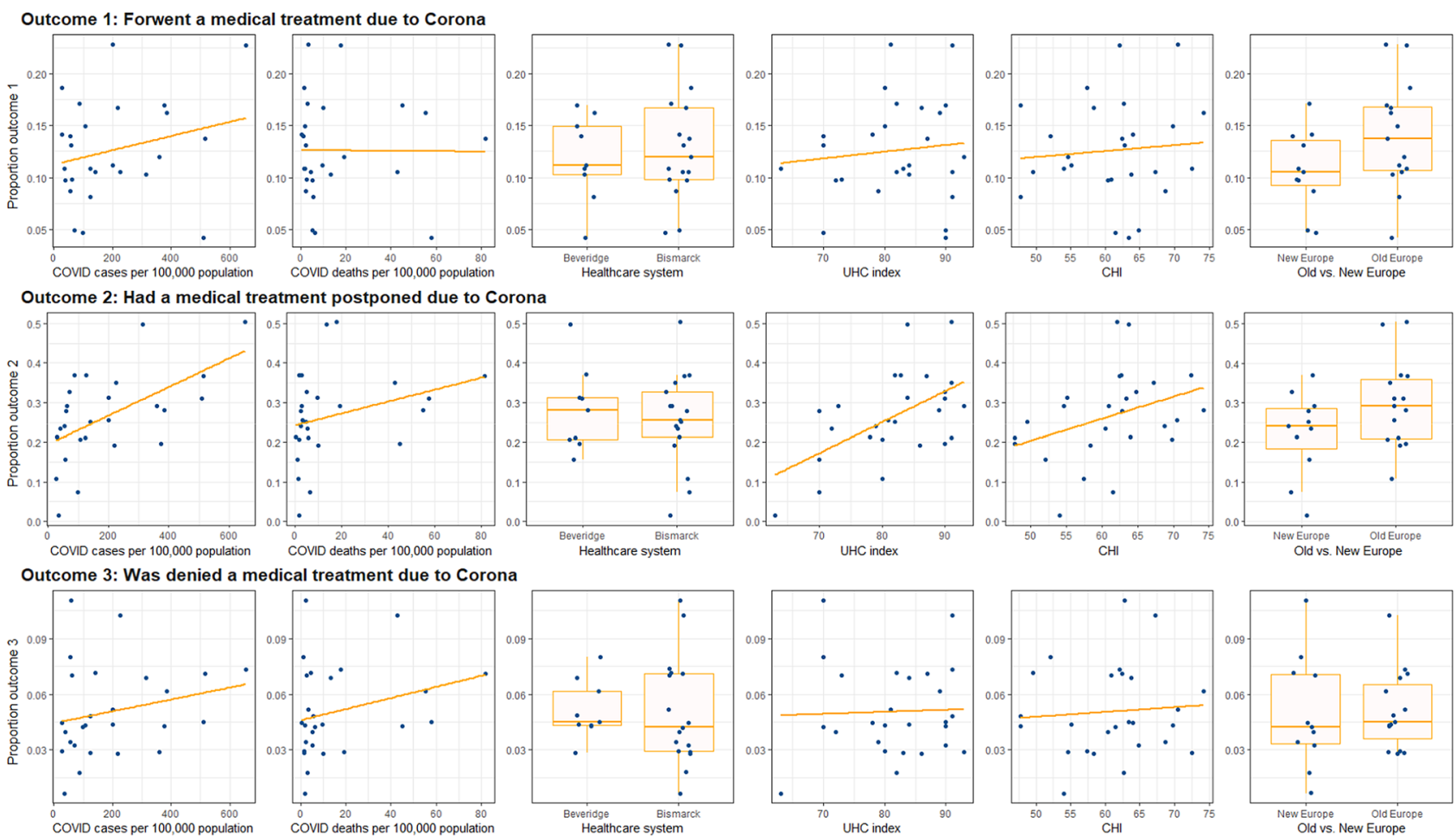

Fig. 2 Association between macro-variables and outcomes. Note: own calculations based on SHARE data and varioussources of country-level data (see the Data and methodssection).

Table 4 Country-context effects (estimates from multilevel random intercept models)

\begin{tabular}{llll}
\hline & $\begin{array}{l}\text { Outcome } \\
\text { 1: For- } \\
\text { went }\end{array}$ & $\begin{array}{l}\text { Outcome } \\
\text { 2: Post- } \\
\text { poned }\end{array}$ & Outcome 3: Denied \\
\hline Cases per 100,000 & 1.001 & $1.002^{* * *}$ & $1.001^{* *}$ \\
Deaths per 100,000 & 1.001 & $1.011^{\mathrm{a}}$ & $1.009^{* *}$ \\
UHC index & 1.013 & $1.068^{* * *}$ & 1.019 \\
$\begin{array}{l}\text { Healthcare system } \\
\text { Bismarck }\end{array}$ & Ref & Ref & Ref \\
$\begin{array}{l}\text { Beveridge } \\
\text { CHI }\end{array}$ & 0.952 & 1.318 & 1.153 \\
'Old' versus 'New' Europe & 1.005 & $1.043^{* *}$ & 1.007 \\
'Old' Europe & Ref & Ref & Ref \\
'New' Europe & $0.654^{* *}$ & $0.552^{* *}$ & 0.815 \\
$\begin{array}{l}\text { Observations } \\
\text { Individual-level }\end{array}$ & 40,919 & 40,919 & 40,919 \\
controls & Yes & Yes & Yes \\
\hline
\end{tabular}

Odds ratio estimates based on combined data from SHARE Wave 7 Release 7.1.1, SHARE Corona Survey Release 0.0.1 beta $(N=40,919)$ and macro-level data from various sources (see text); * $p<0.1, * * p<0.05, * * * p<0.01 ;{ }^{\mathrm{a}} p=0.103$ for different values of each explanatory macro-level variable that was found to be (at least marginally) significant in Table 4.

\section{Discussion}

To the extent of our knowledge, this is the first study that has examined the effects of the epidemic control measures in the outbreak of the COVID-19 pandemic on multiple dimensions of healthcare access for people aged 50+in 25 European countries and Israel. Furthermore, it is a first multinational, harmonised study about the effects of the COVID-19 pandemic on different dimensions of life among people aged 50+in Europe. Our goal in this paper was to explore within- and between-country variations in barriers to accessing healthcare resulting from measures to contain the spread of COVID-19. We studied these barriers using three self-reported measures of forgoing, postponing and being denied healthcare services, while accounting for crossnational differences, features of a country's health system and containment indicators of the pandemic. We used data from the SHARE study and its unique micro-dataset from the SHARE Corona Survey and supplemented these with macro-data - the prevalence of the COVID-19 cases and deaths and health system features. We argued that specific 

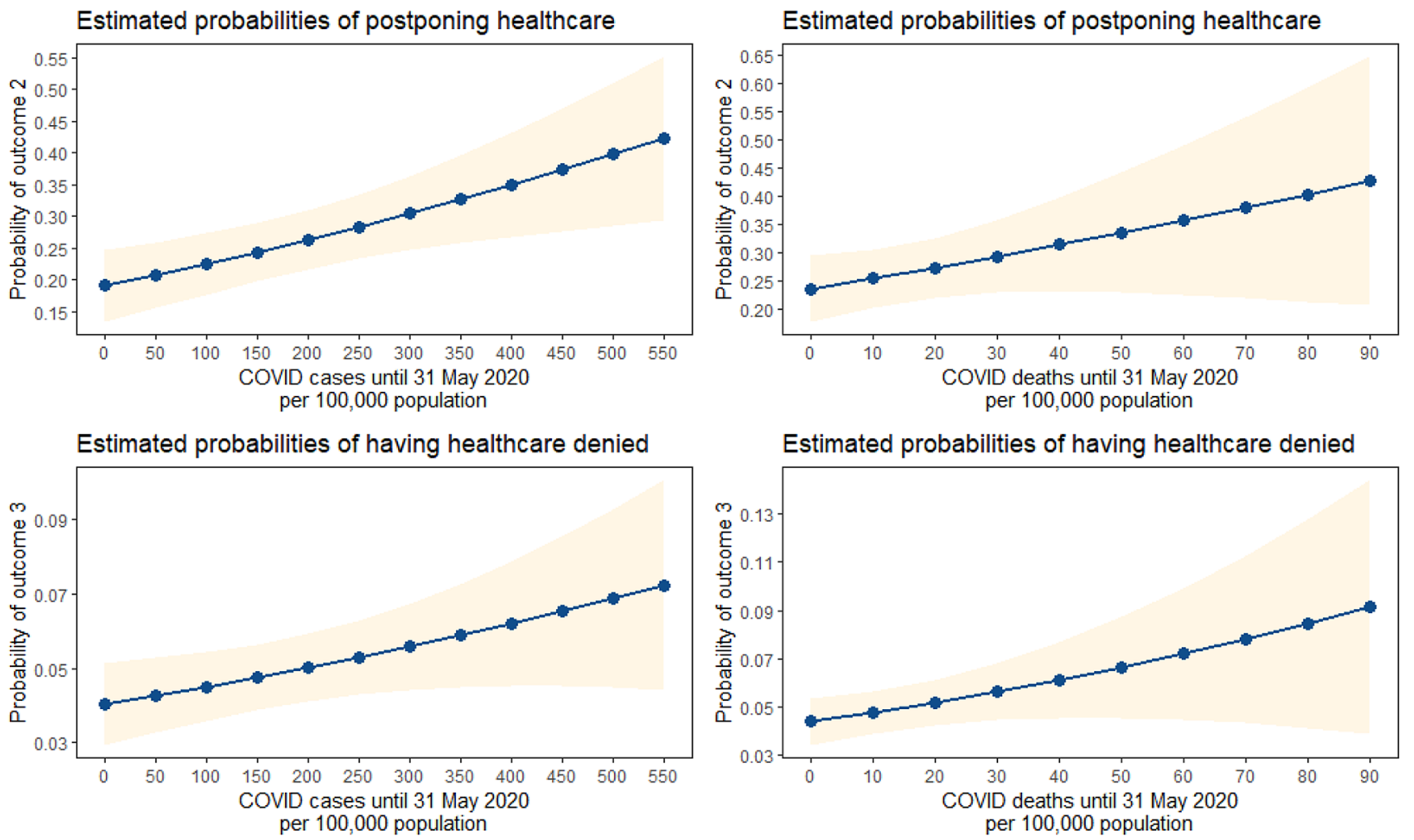

Fig. 3 Predictive margins at specified values of COVID-19 morbidity and mortality macro-variables. Note: own calculations based on SHARE data and various sources of country-level data (see the Data and methods section)
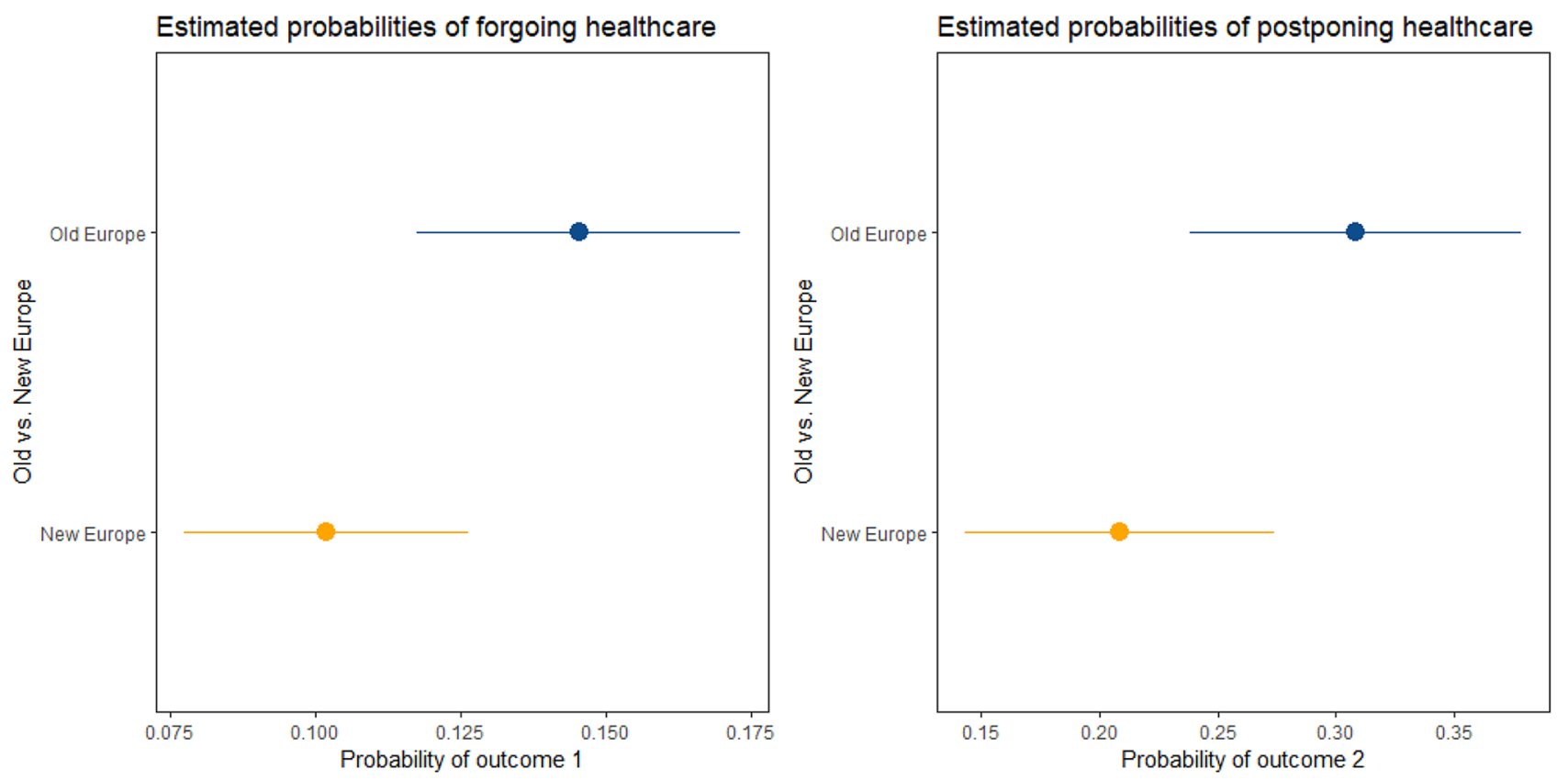

Fig. 4 Predictive margins for 'Old' versus 'New' European countries 


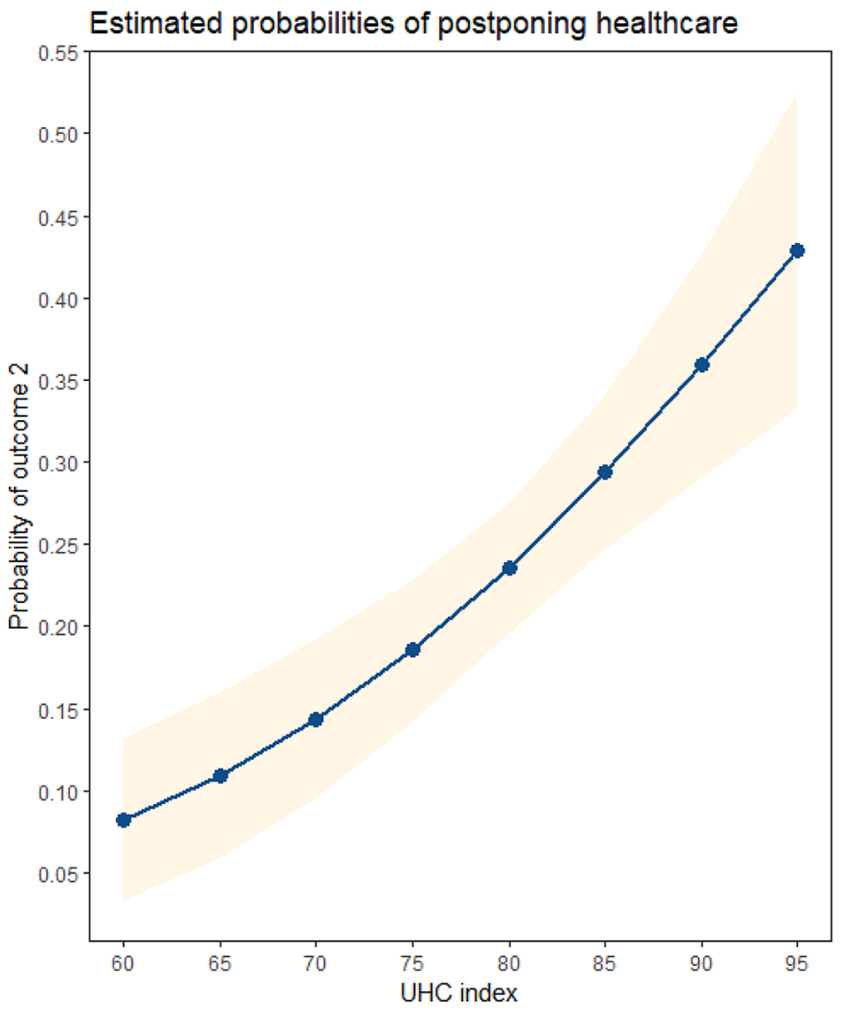

Fig. 5 Predictive margins at specified values of UHC index and CHI

groups of people 50+ were at higher risk of experiencing barriers to accessing healthcare due to the epidemic control decisions. Furthermore, we highlighted the importance of the macro-factors that could be associated with the unmet needs among a population group that is already burdened by the NCDs and is at high-risk of COVID-19 infection. The implications of these findings are discussed separately in the context of the micro- and macro-levels of the analysis.

\section{Micro-determinants}

\section{Demographic characteristics}

Our first research question addressed the determinants of limited access to healthcare due to COVID-19 at the individual level. Our goal was to uncover which groups of people aged 50+ were more likely to report barriers to healthcare in the pandemic. Holding all other variables constant, we found that occupationally active (50-64), sometimes denoted as young-old, were more likely to report forwent, postponed and denied healthcare. Similar findings, but for healthcare forgone due to costs, were reported by Litwin and Sapir (2009). On the other hand, if we consider models with age as the only independent variable, the age effect is much weaker (less negative) or even positive in the case
Estimated probabilities of postponing healthcare

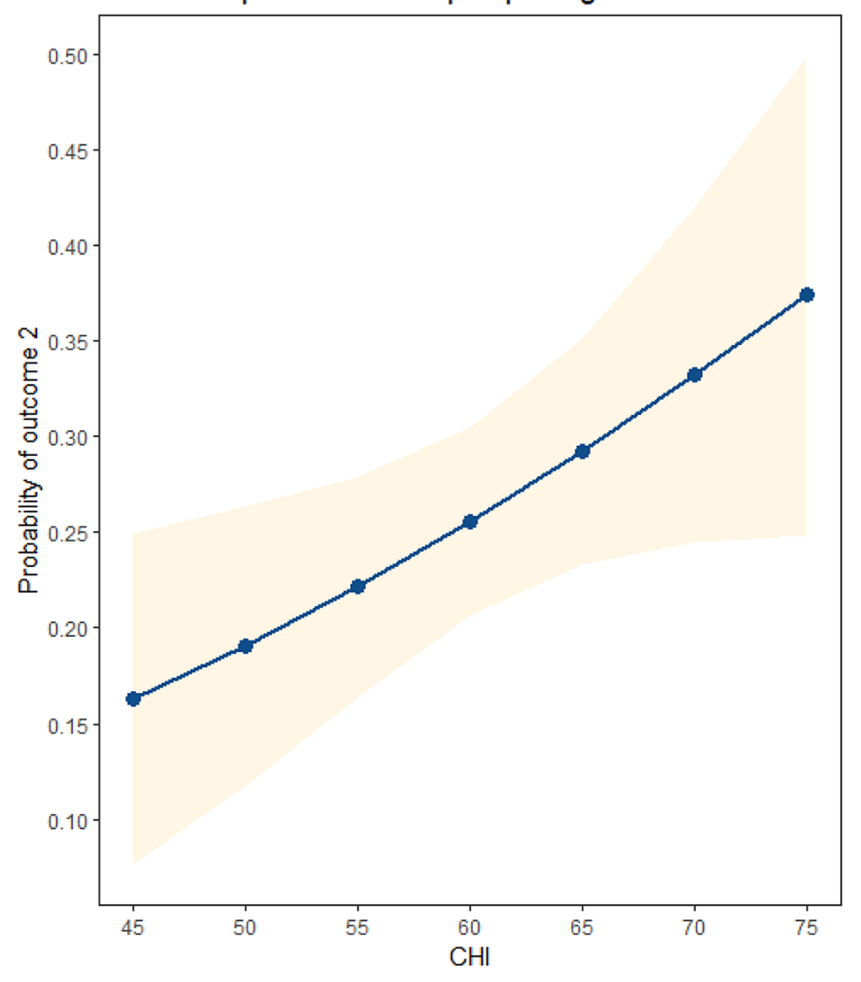

of forwent healthcare for young retirees (65-74) and the older-old $(80+)$ while care is postponed for young retirees. However, including other variables in the models changes the age effect to being negative. Even though the older age is an important predictor of healthcare utilisation (Beard and Bloom 2015; Cantarero-Prieto et al. 2019; Midão et al. 2018), healthcare demand and health spending (Meijer et al. 2013; Reinhardt 2000), it seems to have had a protective effect against forwent, postponed or denied healthcare during the outbreak. It could be that older adults $(65+)$ continued to receive adequate support from others and were not so reluctant in seeking medical care in spite of social distancing and epidemic control measures. The observed gender differences in the likelihood of reporting forgone and postponed healthcare in the outbreak have been validated in many previous studies that employed SHARE data (see, for example, Abuladze et al. 2017; Pirani and Salvini 2012; Santos-Eggimann et al. 2005).

\section{Socio-economic characteristics}

Studies exploring the association of a predisposing factoreducational attainment-and perceived barriers to accessing healthcare services show mixed results. The conclusion of this study, that individuals with higher levels of education were more likely to perceive barriers to accessing healthcare 
due to epidemic control decisions, can be linked with findings of earlier research about the association between education level and unmet healthcare needs in the general population (Allan and Ammi 2020; Allin et al. 2010; Sibley and Glazier 2009). Furthermore, studies confirm that more schooling tends to increase the use of the screening services (Kenkel 1994) and that better educated individuals are more likely to visit doctors (Jürges 2007), to get vaccinated (Schmitz and Wübker 2011) or to engage in more preventive and risk control behaviours (Cutler and Lleras-Muney 2010). Another argument is that better educated older people have higher health literacy (see, for example, Chesser et al. 2016) and thus are more informed about the importance of regular health treatments and generally tend to care more for their health and claim their right to healthcare services. A plausible explanation could be that the sudden outbreak and rapid epidemic control measures have probably disproportionately crowded out this group from their routine use of healthcare. On the other hand, the better educated could have a better understanding of the demands for acute healthcare during a pandemic and therefore do not insist on their regular appointments.

Additionally, we identify a significant negative association between perceived economic status and reported barriers to healthcare access. Economic deprivation turns out to be a strong predictor for reporting forwent or denied healthcare among persons aged $50+$ in this health crisis. Poor economic situation was already found elsewhere to be a strong predictor of unmet healthcare needs among older Europeans (Herr et al. 2014; Mielck et al. 2009; Otero et al. 2003) as well as in the general population (Kasman and Badley 2004; Shi and Stevens 2005; Zavras et al. 2016). Our analysis revealed that people aged $50+$ residing in urban areas were more likely to forgo and to have medical treatment postponed during the COVID-19 outbreak. Although it has been investigated in a limited number of studies on unmet healthcare needs (see, for example, Chen and Hou 2002; Pappa et al. 2013; Zavras et al. 2016), urbanity might be especially interesting in the context of this pandemic. Before the outbreak, urbanity might have been considered as an access facilitator because the density of primary, specialist or hospital healthcare is higher in urban areas $(\mathrm{Cyr}$ et al. 2019; Henning-Smith 2020); this could have reversed after huge numbers of infected patients started to overwhelm health capacities, particularly in the hospitals. In addition, the urban-rural divide in Europe is complex, and some regions in Europe face so-called rural isolation while others experience high levels of wellbeing due to proximity to urban areas. This might have implications for policymakers who should aim to prevent overcrowding of healthcare systems and secure undisturbed access to healthcare for patients with other NCDs. This could be done by facilitating access to primary and preventive healthcare services in rural areas, for example, by using more telemedicine or delivering healthcare via mobile medical teams, which could curtail the pressure to provide hospital healthcare.

\section{Individual health-related characteristics}

We showed that poorer health status described by individual's SRH, chronic conditions or healthcare utilisation (drugs and hospital services) was a significant predictor of perceived barriers in accessing healthcare among people $50+$. This finding has been confirmed in earlier published studies either for samples of older people (Kim et al. 2018; Otero et al. 2003; Thorpe et al. 2011) or in the general population (Kasman and Badley 2004). Going beyond previous studies, we found that individuals whose health worsened after the outbreak had a higher likelihood of reporting barriers to accessing care as measured by all the outcomes. This finding is of special interest as this group would require more attention in the future when it comes to healthcare prioritisation. For these already vulnerable groups, access to healthcare during the outbreak actually got worse. Failing to meet adequate healthcare needs of older people might have two far-reaching consequences: greater health vulnerability for those who did not receive healthcare for other conditions and substantial negative health consequences. Our interpretation is supported by several studies that have found that delayed referrals due to the COVID-19 pandemic increased mortality for patients with chronic conditions (see, for example, Maringe et al. 2020; Sud et al. 2020; Weinberger et al. 2020). Obviously, in the aftermath of this health crisis triggered by the SARS-CoV-2 outbreak, public healthcare systems might experience a great rebound in demand for their resources. To get ready for this spike or 'demand wave', careful planning of health resources, whether of medical staff, medical equipment or medical facility working regimes, is crucial. This strategy could prevent a further increase in health inequalities and improve overall health outcomes.

\section{Macro-determinants}

This study tested whether exogenous factors, for example, the number of COVID-19 deaths and cases, healthcare system features (Bismarck vs. Beveridge), the UHC index, strictness of government policies related to COVID-19 and geographical clustering ('Old' vs. 'New' Europe), were associated with access barriers to healthcare services. We have seen that healthcare systems that had a better UHC effective score in 2019 have been perceived as less successful in controlling the initial spread of the Coronavirus (e.g. Luxembourg, Spain, Belgium, Italy and France). Another interesting finding is the difference between perceived barriers in access to healthcare in countries sometimes described 
as the 'Old' and the 'New' Europe (see, for example, Cristea et al. 2021; Iacovou and Skew 2011; Mälksoo 2009). There is a statistically significant difference in proportions of persons aged 50+ who have forgone or have had medical treatment postponed in countries of 'Old' and 'New' Europe. It has been documented that countries of 'New' Europe, mainly post-socialist countries, were more successful in their response to the COVID-19 crisis in its initial wave. For example, the Czech 'blanket' quarantine and the adoption of strict epidemic control measures in the early stage of the pandemic have been recognised as a 'success' (Kouřil and Ferenčuhová 2020), in contrast to developments in some of the most affected countries of 'Old' Europe, like France, Italy and Spain (Ceylan 2020; Saglietto et al. 2020). Obviously, policies intended to contain the epidemic in 'New' Europe did not result in higher likelihoods of forgoing medical treatment due to fear of infection or postponement of scheduled medical appointments by healthcare providers. It could be that more eager epidemic control measures in the post-socialist countries have had positive effects on their more fragile healthcare systems.

\section{Study limitations}

We are aware that this paper has several limitations. To begin with, unlike previous empirical studies, our investigation used a non-standard set of outcome variables to assess the unmet healthcare needs of people aged 50+; that is, the variables were all related to epidemic control decisions. Thus, comparisons with earlier studies could be misleading but should improve when the data from the follow-up research, the second round of the SHARE Corona Survey planned for 2021, becomes available. Another limitation of our study is the inability to differentiate between respondents with no need for healthcare and respondents whose needs for healthcare were met. The calculated estimates of difficulties in access to healthcare might be biased downwards because the survey population at risk in the denominator also included respondents who answered 'no' to the questions on our three outcome variables but in reality had no need for healthcare. Our study is not the first to encounter such a survey design issue (OECD 2019), but we attenuate it using a rich set of health-related controls from SHARE Wave 7. While aware of this limitation, we believe that our findings are still useful in revealing within- and between-country variations in access to healthcare during the SARS-CoV-2 outbreak. Last but not least, it is worthwhile to mention that the second wave of the SHARE Corona Survey will allow future studies to explore the longitudinal dimension of the data and upgrade this study and our understanding of health-related and socio-economic impacts of the crisis.
Acknowledgements This publication is based on Survey of Health, Ageing and Retirement in Europe (SHARE) Wave 8. COVID-19 Survey 1. Release version: 0.0.1. beta (Börsch-Supan 2020a). Please see Scherpenzeel et al. (2020) for methodological details. In addition, this paper uses data from SHARE Wave 7 (https://doi.org/10.6103/ SHARE.w7.711), see Börsch-Supan et al. (2013) for methodological details. The SHARE data collection has been funded by the European Commission through FP5 (QLK6-CT-2001-00360), FP6 (SHARE-I3: RII-CT-2006-062193, COMPARE: CIT5-CT-2005-028857, SHARELIFE: CIT4-CT-2006-028812), FP7 (SHARE-PREP: GA N²11909, SHARE-LEAP: GA N ${ }^{\circ} 227822$, SHARE M4: GA N²61982, DASISH: GA N ${ }^{\circ} 283646$ ) and Horizon 2020 (SHARE-DEV3: GA N676536, SHARE-COHESION: GA N870628, SERISS: GA N654221, SSHOC: GA $N^{\circ} 823782$, SHARE-COVID19: GA $\left.N^{\circ} 101015924\right)$ and by DG Employment, Social Affairs \& Inclusion. Additional funding from the German Ministry of Education and Research, the Max Planck Society for the Advancement of Science, the U.S. National Institute on Aging (U01_AG09740-13S2, P01_AG005842, P01_AG08291, P30_AG12815, R21_AG025169, Y1-AG-4553-01, IAG_BSR06-11, OGHA_04-064, HHSN271201300071C) and from various national funding sources is gratefully acknowledged (see www.share-project. org)

Availability of data and material Publically available.

Code availability Available on request from the authors.

\section{References}

Abuladze L, Kunder N, Lang K, Vaask S (2017) Associations between self-rated health and health behaviour among older adults in Estonia: a cross-sectional analysis. BMJ Open. https://doi.org/10.1136/ bmjopen-2016-013257

Allan I, Ammi M (2020) Evolution of the determinants of unmet healthcare needs in a universal healthcare system: Canada, 20012014. Health Econ Policy L. https://doi.org/10.1017/S174413312 0000250

Allin S, Grignon M, Le Grand J (2010) Subjective unmet need and utilization of healthcare services in Canada: what are the equity implications? Soc Sci Med 70:465-472. https://doi.org/10.1016/j. socscimed.2009.10.027

Allin S, Masseria C, Mossialos E (2009) Measuring socioeconomic differences in use of healthcare services by wealth versus by income. Am J Public Health 99:1849-1855. https://doi.org/10.2105/AJPH. 2008.141499

Alonso J, Orfila F, Ruigómez A et al (1997) Unmet healthcare needs and mortality among Spanish elderly. Am J Public Health 87:365370. https://doi.org/10.2105/AJPH.87.3.365

Andersen RM (1995) Revisiting the behavioral model and access to medical care: does it matter? J Health Soc Behav. https://doi.org/ $10.2307 / 2137284$

Angelico R, Trapani S, Manzia TM et al (2020) The COVID-19 outbreak in Italy: Initial implications for organ transplantation programs. Am J Transplant 20:1780-1784. https://doi.org/10.1111/ ajt. 15904

Beard JR, Bloom DE (2015) Towards a comprehensive public health response to population ageing. Lancet 385:658-661. https://doi. org/10.1016/S0140-6736(14)61461-6

Bergman H, Karunananthan S, Robledo LMG et al (2013) Understanding and meeting the needs of the older population: a global challenge. Can Geri J 16:61-65. https://doi.org/10.5770/cgj.16.60

Börsch-Supan A, Brandt M, Hunkler C et al (2013) Data resource profile: the survey of health, ageing and retirement in Europe 
(SHARE). Int J Epidemiol 42:992-1001. https://doi.org/10.1093/ $\mathrm{ije} / \mathrm{dyt} 088$

Börsch-Supan A (2020a) Survey of health, ageing and retirement in Europe (SHARE) Wave 8. COVID-19 Survey 1. Release version: 0.0.1. beta. SHARE-ERIC. Data set. https://doi.org/10.6103/ SHARE.w8cabeta.001

Börsch-Supan A (2020b) Survey of health, ageing and retirement in Europe (SHARE) Wave 7. Release version: 7.1.1. SHARE-ERIC. Data set. https://doi.org/10.6103/SHARE.w7.711

Börsch-Supan A (2020c) Survey of health, ageing and retirement in Europe (SHARE) Wave 8. COVID-19 survey 1 interview date. Release version: 0.0.1. beta. SHARE-ERIC. Data set. https://doi. org/10.6103/SHARE.w8caintdbeta.001

Cantarero-Prieto D, Pascual-Sáez M, Blázquez-Fernández C (2019) Does social isolation affect medical doctor visits? New evidence among European older adults. Appl Res Qual Life. https://doi.org/ 10.1007/s11482-019-09795-0

Ceylan Z (2020) Estimation of COVID-19 prevalence in Italy, Spain, and France. Sci Total Environ. https://doi.org/10.1016/j.scitotenv. 2020.138817

Chaupain-Guillot S, Guillot O (2015) Health system characteristics and unmet care needs in Europe: an analysis based on EU-SILC data. Eur J Health Econ 16:781-796. https://doi.org/10.1007/ s10198-014-0629-x

Chen J, Hou F (2002) Unmet needs for healthcare. Health Rep 13:23-34

Chesser AK, Woods NK, Smothers K, Rogers N (2016) Health literacy and older adults: a systematic review. Gerontol Geriatr Med 2:1-13. https://doi.org/10.1177/2333721416630492

Clark A, Jit M, Warren-Gash C et al (2020) Global, regional, and national estimates of the population at increased risk of severe COVID-19 due to underlying health conditions in 2020: a modelling study. Lancet Glob Health 8:1003-1017. https://doi.org/10. 1016/S2214-109X(20)30264-3

Cristea M, Noja GG, Jurcuţ C-N et al (2021) The interplay between public health, well-being and population aging in Europe: an advanced structural equation modelling and Gaussian Network Approach. Int J Environ Res Public Health. https://doi.org/10. 3390/ijerph18042015

Cutler DM, Lleras-Muney A (2010) Understanding differences in health behaviors by education. J Health Econ 29:1-28. https:// doi.org/10.1016/j.jhealeco.2009.10.003

Cylus J, Papanicolas I (2015) An analysis of perceived access to healthcare in Europe: how universal is universal coverage? Health Policy 119:1133-1144. https://doi.org/10.1016/j.healthpol.2015.07.004

Cyr ME, Etchin AG, Guthrie BJ, Benneyan JC (2019) Access to specialty healthcare in urban versus rural US populations: a systematic literature review. BMC Health Serv Res 19:974. https://doi. org/10.1186/s12913-019-4815-5

de Meijer C, Wouterse B, Polder J, Koopmanschap M (2013) The effect of population aging on health expenditure growth: a critical review. Eur J Ageing 10:353-361. https://doi.org/10.1007/ s10433-013-0280-x

De Rosa S, Spaccarotella C, Basso C et al (2020) Reduction of hospitalizations for myocardial infarction in Italy in the COVID-19 era. Eur Heart J 41:2083-2088. https://doi.org/10.1093/eurheartj/ ehaa409

Doetsch J, Pilot E, Santana P, Krafft T (2017) Potential barriers in healthcare access of the elderly population influenced by the economic crisis and the troika agreement: a qualitative case study in Lisbon. Portugal Int J Equity Health. https://doi.org/ 10.1186/s12939-017-0679-7

Douglas M, Katikireddi SV, Taulbut M et al (2020) Mitigating the wider health effects of covid-19 pandemic response. BMJ. https://doi.org/10.1136/bmj.m1557
ECDC (2020) European Centre for Disease Prevention and Control: COVID-19 data. https://www.ecdc.europa.eu/en/covid-19/data. Accessed 8 Dec 2020

European Commission. Statistical Office of the European Union (Eurostat) (2016) HEDIC: health expenditures by diseases and conditions: 2016 (edn). Publications Office, LU https://doi.org/ $10.2785 / 434142$

Eurostat (2020a) Population on 1 January by age and sex [demo_ pjan]. https://ec.europa.eu/eurostat/web/population-demog raphy-migration-projections/data/database. Accessed 9 Sep 2020

Eurostat (2020b) Self-reported unmet needs for medical examination by sex, age, main reason declared and income quintile [hlth silc_08]. https://ec.europa.eu/eurostat/databrowser/product/view/ HLTH_SILC_08?lang=en. Accessed 14 Dec 2020

Goddard M, Smith P (2001) Equity of access to healthcare services: theory and evidence from the UK. Soc Sci Med 53:1149-1162. https://doi.org/10.1016/S0277-9536(00)00415-9

Gulliford M, Figueroa-Munoz J, Morgan M, Hughes D, Gibson B, Beech R, Hudson M (2002) What does "access to health care" mean? J Health Serv Res Policy 7:186-188. https://doi.org/10. 1258/135581902760082517

Hale T, Webster S, Petherick A, Phillips T, Kira B (2020) Oxford COVID-19 Government response tracker, Blavatnik School of Government. Data use policy: creative commons attribution CC BY standard

Henning-Smith C (2020) The unique impact of COVID-19 on older adults in rural areas. J Aging Soc Policy 32:396-402. https://doi. org/10.1080/08959420.2020.1770036

Herr M, Arvieu J-J, Aegerter P et al (2014) Unmet healthcare needs of older people: prevalence and predictors in a French cross-sectional survey. Eur J Public Health 24:808-813. https://doi.org/10.1093/ eurpub/ckt179

Iacovou M, Skew AJ (2011) Household composition across the new Europe: where do the new Member States fit in? Demogr Res 25:465-490. https://doi.org/10.4054/DemRes.2011.25.14

Jürges H (2007) Health insurance status and physician-induced demand for medical services in Germany: new evidence from combined district and individual level data. SSRN J. https://doi.org/10.2139/ ssrn. 1092811

Kasman NM, Badley EM (2004) Beyond access: who reports that healthcare is not being received when needed in a publicly-funded healthcare system? Can J Public Health 95:304-308. https://doi. org/10.1007/BF03405137

Kenkel DS (1994) The demand for preventive medical care. Appl Econ 26:313-325. https://doi.org/10.1080/00036849400000078

Kim Y-S, Lee J, Moon Y et al (2018) Unmet healthcare needs of elderly people in Korea. BMC Geriatr 18:98. https://doi.org/10.1186/ s12877-018-0786-3

Kissler SM, Tedijanto C, Goldstein E et al (2020) Projecting the transmission dynamics of SARS-CoV-2 through the postpandemic period. Science. https://doi.org/10.1126/science.abb5793

Ko H (2016) Unmet healthcare needs and health status: panel evidence from Korea. Health Policy 120:646-653. https://doi.org/10.1016/j. healthpol.2016.04.005

Kouřil P, Ferenčuhová S (2020) "Smart" quarantine and "blanket" quarantine: the Czech response to the COVID-19 pandemic. Eurasian Geogr Econ 61:587-597. https://doi.org/10.1080/15387216. 2020.1783338

Lindström C, Rosvall M, Lindström M (2020) Unmet health-care needs and mortality: a prospective cohort study from southern Sweden. Scand J Public Health 48:267-274. https://doi.org/10.1177/14034 94819863530

Litwin H, Sapir EV (2009) Forgone healthcare due to cost among older adults in European countries and in Israel. Eur J Ageing 6:167176. https://doi.org/10.1007/s10433-009-0126-8 
Lozano R, Fullman N, Mumford JE et al (2020) Measuring universal health coverage based on an index of effective coverage of health services in 204 countries and territories, 1990-2019: a systematic analysis for the Global Burden of Disease Study 2019. Lancet 396:1250-1284. https://doi.org/10.1016/S0140-6736(20)30750-9

Mälksoo M (2009) The memory politics of becoming European: the East European subalterns and the collective memory of Europe. Eur J Int Relat 15:653-680. https://doi.org/10.1177/1354066109 345049

Maringe C, Spicer J, Morris M et al (2020) The impact of the COVID19 pandemic on cancer deaths due to delays in diagnosis in England, UK: a national, population-based, modelling study. Lancet Oncol 21:1023-1034. https://doi.org/10.1016/S1470-2045(20) 30388-0

Midão L, Giardini A, Menditto E et al (2018) Polypharmacy prevalence among older adults based on the survey of health, ageing and retirement in Europe. Arch Gerontol Geriatr 78:213-220. https:// doi.org/10.1016/j.archger.2018.06.018

Mielck A, Kiess R, von dem Knesebeck O et al (2009) Association between forgone care and household income among the elderly in five Western European countries-analyses based on survey data from the SHARE-study. BMC Health Serv Res. https://doi.org/ $10.1186 / 1472-6963-9-52$

Neri MT, Kroll T (2003) Understanding the consequences of access barriers to health care: experiences of adults with disabilities. Disabil Rehabil 25:85-96. https://doi.org/10.1080/0963828021 000007941

OECD (2019) Health for everyone?: social inequalities in health and health systems. OECD Health Policy Stud OECD Publ Paris. https://doi.org/10.1787/3c8385d0-en

Oliver A, Mossialos E (2004) Equity of access to healthcare: outlining the foundations for action. J Epidemiol Commun $\mathrm{H}$ 58:655-658. https://doi.org/10.1136/jech.2003.017731

Osborn R, Moulds D, Squires D et al (2014) International survey of older adults finds shortcomings in access, coordination, and patient-centered care. Health Affair 33:2247-2255. https://doi.org/ 10.1377/hlthaff.2014.0947

Otero Á, de Yébenes MJG, Rodríguez-Laso Á, Zunzunegui MV (2003) Unmet home care needs among community-dwelling elderly people in Spain. Aging Clin Exp Res 15:234-242. https://doi.org/10. 1007/BF03324504

Palmer K, Monaco A, Kivipelto M et al (2020) The potential longterm impact of the COVID-19 outbreak on patients with noncommunicable diseases in Europe: consequences for healthy ageing. Aging Clin Exp Res 32:1189-1194. https://doi.org/10.1007/ s40520-020-01601-4

Pappa E, Kontodimopoulos N, Papadopoulos A et al (2013) Investigating unmet health needs in primary healthcare services in a representative sample of the Greek population. Int J Env Res Pub He 10:2017-2027. https://doi.org/10.3390/ijerph10052017

Paterlini M (2020) On the front lines of coronavirus: the Italian response to covid-19. BMJ m1065. https://doi.org/10.1136/bmj. $\mathrm{m} 1065$

Peters DH, Garg A, Bloom G et al (2008) Poverty and access to healthcare in developing countries. Ann NY Acad Sci 1136:161-171. https://doi.org/10.1196/annals.1425.011

Pirani E, Salvini S (2012) Socioeconomic inequalities and self-rated health: a multilevel study of Italian elderly. Popul Res Policy Rev 31:97-117. https://doi.org/10.1007/s11113-011-9219-0

Quesnel-Vallée A, Willson A, Reiter-Campeau S (2016) Health inequalities among older adults in developed countries: reconciling theories and policy approaches. In: George L, Ferraro K (eds) Handbook of aging and the social sciences, 8th (edn), Elsevier Academic Press, pp 483-502
R Core Team (2020). R: a language and environment for statistical computing, R Foundation for Statistical Computing, Vienna, Austria. https://www.R-project.org/

Reinhardt UE (2000) Healthcare for the aging baby boom: lessons from Abroad. J Econ Perspect 14:71-83. https://doi.org/10.1257/ jep.14.2.71

Saglietto A, D’Ascenzo F, Zoccai GB, De Ferrari GM (2020) COVID19 in Europe: the Italian lesson. Lancet 395:1110-1111. https:// doi.org/10.1016/S0140-6736(20)30690-5

Santos-Eggimann B, Junod J, Cornaz S (2005) Health service utilisation in older Europeans. In: Börsch-Supan A (ed) Health, ageing and retirement in Europe first results from the survey of health, ageing and retirement in Europe, Mannheim Research Institute for the Economics of Aging (MEA), pp 133-140

Scherpenzeel A, Axt K, Bergmann M et al (2020) Collecting survey data among the 50+ population during the COVID-19 outbreak: the survey of health, ageing and retirement in Europe (SHARE). Surv Res Methods 14:217-221. https://doi.org/10.18148/SRM/ 2020.V14I2.7738

Schmitz H, Wübker A (2011) What determines influenza vaccination take-up of elderly Europeans? Health Econ 20:1281-1297. https:// doi.org/10.1002/hec.1672

Shi L, Stevens GD (2005) Vulnerability and unmet healthcare needs: the influence of multiple risk factors. J Gen Intern Med 20:148154. https://doi.org/10.1111/j.1525-1497.2005.40136.x

Sibley LM, Glazier RH (2009) Reasons for self-reported unmet healthcare needs in Canada: a population-based provincial comparison. Health Policy 5:87-101. https://doi.org/10.12927/hcpol.2009. 20934

Siciliani L, Verzulli R (2009) Waiting times and socioeconomic status among elderly Europeans: evidence from SHARE. Health Econ 18:1295-1306. https://doi.org/10.1002/hec.1429

Srakar A, Hren R, Rupel VP (2016) Health services utilization in Older Europeans: an empirical study. Organizacija 49:127-136. https:// doi.org/10.1515/orga-2016-0009

StataCorp (2019) Stata statistical software: release 16 StataCorp LLC College Station, TX

Sud A, Torr B, Jones ME et al (2020) Effect of delays in the 2-weekwait cancer referral pathway during the COVID-19 pandemic on cancer survival in the UK: a modelling study. Lancet Oncol 21:1035-1044. https://doi.org/10.1016/S1470-2045(20)30392-2

Tanne JH, Hayasaki E, Zastrow M et al (2020) Covid-19: how doctors and healthcare systems are tackling coronavirus worldwide. BMJ. https://doi.org/10.1136/bmj.m1090

Terraneo M (2015) Inequities in healthcare utilization by people aged 50+: evidence from 12 European countries. Soc Sci Med 126:154-163. https://doi.org/10.1016/j.socscimed.2014.12.028

Thorpe JM, Thorpe CT, Kennelty KA, Pandhi N (2011) Patterns of perceived barriers to medical care in older adults: a latent class analysis. BMC Health Serv Res. https://doi.org/10.1186/ 1472-6963-11-181

Volpato S, Landi F, Incalzi RA (2020) A frail healthcare system for an old population: lesson form the COVID-19 outbreak in Italy. J Gerontol A Biol 75:126-127. https://doi.org/10.1093/gerona/ glaa087

Weinberger DM, Chen J, Cohen T et al (2020) Estimation of excess deaths associated with the COVID-19 pandemic in the United States, March to May 2020. JAMA Intern Med 180:1336

Wickham H (2016) Ggplot2: elegant graphics for data analysis. Springer-Verlag, New York

Williams GA, Cylus J, Roubal T, Ong P, Barber S (2019) Sustainable health financing with an ageing population. Will population ageing lead to uncontrolled health expenditure growth? European Observatory on Health Systems and Policies. https://www.ncbi. nlm.nih.gov/books/NBK550604/. Accessed 12 Dec 2020 
World Health Organisation (WHO), United Nations Development Programme (UNDP) (2020) Responding to non-communicable diseases during and beyond the COVID-19 pandemic: State of the evidence on COVID-19 and non-communicable diseases: a rapid review. Geneva: World Health Organization and the United Nations Development Programme. https://www.who.int/publicatio ns/i/item/WHO-2019-nCoV-Non-communicable_diseases-Evide nce-2020.1. Accessed 15 Dec 2020

World Health Organization (WHO) (2020a) WHO Director-General's opening remarks at the media briefing on COVID-19, 11 March 2020. https://www.who.int/director-general/speeches/detail/ who-director-general-s-opening-remarks-at-the-media-brief ing-on-covid-19---11-march-2020

World Health Organisation (WHO) (2020b) Pulse survey on continuity of essential health services during the COVID-19 pandemic: interim report, 27 August 2020. World Health Organization. https://apps.who.int/iris/handle/10665/334048.

Zavras D, Zavras AI, Kyriopoulos I-I, Kyriopoulos J (2016) Economic crisis, austerity and unmet healthcare needs: the case of Greece. BMC Health Serv Res. https://doi.org/10.1186/s12913-016-1557510.1186/s12913-016-1557-5

Publisher's Note Springer Nature remains neutral with regard to jurisdictional claims in published maps and institutional affiliations. 